\title{
O Inevitável Exercício de Todas as Lógicas na Meditação
}

\section{The Inevitable Exercise of All Logics in Meditation}

\author{
Esteban Lopez Moreno \\ Programa de Pós-Graduação em História das Ciências e das Técnicas e Epistemologia \\ (HCTE) e Programa de Pós Graduação em Ensino de Química (PEQUI), Universidade \\ Federal do Rio de Janeiro (UFRJ) \\ Fundação Centro de Ciências e Educação Superior a Distância do Estado do Rio de \\ Janeiro (Cecierj) \\ estebanlmoreno@gmail.com \\ orcid.org/0000-0001-8751-2049 \\ Mércio Pereira Gomes \\ Programa de Pós-Graduação em História das Ciências e das Técnicas e Epistemologia \\ (HCTE), Universidade Federal do Rio de Janeiro (UFRJ) \\ merciogomes@gmail.com \\ orcid.org/0000-0001-7731-273X
}

Resumo. Neste artigo ampliamos a trilha já percorrida pelo personagem Pedro, criado pelo filósofo carioca Luiz Sérgio Coelho de Sampaio em seu esforço para tornar mais acessível o seu Sistema Lógico Hiperdialético (SHL). Mostraremos Pedro agora em sua trajetória de praticar meditação, na qual se desvelam operantes os quatro modos básicos de ser e de pensar: a lógica de Identidade (I), a lógica da diferença (D), a dialética (I/D), a lógica sistêmica (D/2), e mais um pensar síntese das anteriores, correspondente à lógica hiperdialética (I/D/2). A cada um desses modos corresponde um modo de percepção da realidade.

Palavras-chave: Meditação. Hiperdialética. Lógica. Luiz Sérgio Coelho de Sampaio.

Abstract. In this article we expand the trail already covered by the character Pedro, created by the Rio de Janeiro philosopher Luiz Sérgio Coelho de Sampaio in his effort to make his Hiperdialético Logical System (SHL) more accessible. We will now show Pedro in his trajectory of practicing meditation, in which the four basic ways of being and thinking are revealed: the logic of Identity (I), the logic of difference $(D)$, the dialectic $(I / D)$, the systemic logic $(D / 2)$, and another thinking 
synthesis of the previous ones, corresponding to hyperdialetic logic $(I / D / 2)$. Each

of these modes corresponds to a way of perceiving reality.

Keywords: Meditation. Hyperdialetics. Logic. Luiz Sérgio Coelho de Sampaio.

Recebido: 01/10/2018 Aceito: 27/10/2018 Publicado: 05/11/2018

\section{Introdução}

Nascido no bairro de Vila Isabel, no Rio de Janeiro, o filósofo Luiz Sérgio Coelho de Sampaio (1933-2003) dedicou boa parte de sua vida, conforme suas próprias palavras, "à explicitação dos determinantes lógicos (a priori) de cada um dos grandes campos do conhecimento, na esperança de chegar, oxalá, a um "compacto" do saber formal básico do Ocidente". Seu objetivo era ousado e foi, ao menos para nós, cumprido por meio da configuração de seu Sistema Lógico Hiperdialético (SHL) (SAMPAIO, 2000, 2001). Entretanto, o SHL tem sido ainda pouco compreendido e difundido mesmo em meio acadêmico, onde poderíamos supor que haveria maior receptividade.

Em 2002, próximo ao final de sua vida, Sampaio publicou uma pequena crônica intitulada: "O inevitável exercício cotidiano de todas as lógicas" (SAMPAIO, 2002), com o objetivo tornar mais palatável ao público o seu sistema. Neste, ele provoca-nos com um personagem imaginário, o Pedro, que a partir de situações corriqueiras, como a cantarolar o "Feitiço da Vila" de Noel Rosa em uma mesa de bar do Seu Amaro, nos revela a presença constante e encantadora de cada uma de "suas" cinco lógicas.

O "esquema de Sampaio", conforme também tem sido denominado, não se reduz aos acontecimentos externos, a exemplo da experiência vivenciada pelo Pedro. As relações lógicas mostram-se também claras ao penetrarmos no mundo psíquico, tendo como território de análise a nossa própria mente.

Neste trabalho propomos um novo ensaio ficcional com o mesmo protagonista, o Pedro, mas desta vez imbuído em praticar meditação. Todos os exemplos estão longe de serem exaustivos, contudo permitem certificar-nos da pertinência do funcionamento das lógicas de Sampaio, no caso, a mente do Pedro. Sigamo-lo!

\section{Ensaio inevitável}

O leve tilintar de um sino demarca o início da prática meditativa. Até chegar àquele momento, Pedro ultrapassou uma longa jornada, entremeada de incertezas e ceticismo. Muitos foram os que alegaram que a meditação proporcionaria estados de maior leveza emocional, paz ou amplitude mental. Por outro lado, vários motivos tornaram este desafio praticamente insuperável. Aquilo, francamente, parecia perda de tempo, deveria existir coisas mais interessantes a descobrir, além de suas muitas tarefas ainda por terminar. Mas 
Pedro se mostrou persistente e, enfim, aceitou o convite para experimentar uma seção meditativa.

Ali estava sentado sobre um zafu surrado, com uma calça de moletom confortável, uma camisa leve, de simples algodão. $\mathrm{O}$ ambiente era tranquilo e limpo, outras pessoas ocupavam sentados alinhadamente o salão. Todos ouviram atentamente as orientações prévias do instrutor sobre como sentar corretamente: manter a coluna ereta, cabeça levemente inclinada, as pernas preferencialmente dobradas uma sobre a outra, com o quadril a um nível superior aos joelhos, de maneira a prover um conforto adequado à prática. Aprendeu também que uma das alternativas de condução era manter atenção constante com a respiração, retendo a consciência no momento presente, evitando se distrair e se apegar a qualquer pensamento. Pedro sentia ter plena clareza da proposta, o desafio de permanecer sentado em silêncio naquela posição pareceu-lhe simples.

Após alguns minutos, Pedro percebeu o burburinho de pessoas conversando do lado de fora, e, por algum motivo irresistível, distraiu-se e começou a prestar atenção à conversa. Logo se lembrou de um papo recente que tivera com um amigo sobre política, o que lhe causou certa amargura, pois o encontro não tinha sido bem-sucedido. Pronto deu-se conta que a posição de seus pés friccionando sobre o tapete agora lhe causavam incômodo, mas nada se comparava à vontade abrupta de coçar o nariz. Talvez fosse uma mosca, pensou, mas de repente, várias comichões começaram a brotar pelo seu corpo, forçando-o a tomar a atitude de coçar algumas regiões mais críticas, contrariando as orientações iniciais. Fêlo, bem verdade, com bastante discrição, contudo como era muito cioso em não perverter a ordem estabelecida, aquilo causou-lhe desassossego e culpa. Por um ou dois instantes, lembrou-se saudoso do refrigerante bem gelado no bar do Seu Amaro.

Depois de alguns minutos iniciais, sua mente já pululava de eventos. Era a conta do mês que não tinha fechado, a namorada da qual sentia falta e, novamente, a conversa com o amigo. Tentava lembrar, por que, afinal, tinham se desentendido por tão pouco. Isso o fez lembrar de uma discussão que tivera com seu pai, anos antes, que o obrigara a deixar de falar com ele um bom tempo. Ocorreu-lhe então um vislumbre de que poderia ter agido de outra forma, mas logo desviou para outro pensamento. Depois de algum momento, sentiu um impulso visceral de olhar o relógio para ver quanto tempo faltava para terminar. Olhou de soslaio, ainda faltava muito, lamentou-se.

A constatação era dura, mas necessária: Pedro não estava conseguindo meditar. A paz que tanto almejava naufragou em um enorme turbilhão de sentimentos, sensações e pensamentos. Sentia-se fracassado, cético consigo. Será que os outros estão passando pela mesma dificuldade? Talvez essa informação lhe servisse de consolo. O sino finalmente toca, indicando o término daquela sua primeira e fracassada experiência meditativa.

Apesar de frustrado, Pedro não havia de desistir. Lembrava de todo esforço que despendeu para decidir a meditar e, ainda que não tivesse alcançado alguma experiência significante, sentia-se seduzido a tentar novamente. Ao longo de sua vivência, se viu forçado a considerar todos aqueles acontecimentos que permearam seus longos minutos 
de prática como parte de si próprio. Era, pois, um paradoxo. Havia um conflito intrínseco entre aquilo que considerava como sua própria identidade, mas que contrastava com outro reino múltiplo, incerto e indômito que o inundava. Se quisesse permanecer no intento meditativo, não bastava usar sua força de vontade, teria que assumir uma outra estratégia. Buscou assumir, pois, a postura de um observador atento àqueles aspectos que saltitavam em sua mente, e conforme desenvolvia maior experiência, compreendia como parte de si mesmo e não se deixava subjugar tão facilmente pelos pensamentos, sensações ou emoções. Em alguns momentos até os impedindo antes mesmo que surgissem; em outras vezes, porém, tomado por eles. Era um reino sutil que ainda perscrutava desajeitadamente.

Após algum tempo, Pedro percebeu que quando um pensamento brotava na consciência, seu automatismo psíquico fazia com que procurasse rapidamente dar um significado a ele. Aos poucos foi adquirindo a capacidade de coordenar seus diferentes pensamentos que reduziam o alcance de sua prática meditativa. Percebia que havia pensamentos que surgiam apenas como imagens, outros em palavras e até mesmo frases. Compreendeu também que havia sempre uma emoção principal vinculada a esses pensamentos, que podia ser desagradável ou prazerosa. Por vezes reagia a um pensamento criando outro, ou usava outro pensamento, que denominou de "ativo", para manter a condução de sua prática meditativa. E, principalmente, começou a compreender a existência de um padrão mais frequente que o desviava de seu intento, a qual conseguiu relacionar a vivências anteriores. Com efeito, sentia ter logrado entender algumas de suas crenças, indecisões e angústias e, portanto, alcançado maior autoconhecimento.

Ao longo de suas vivências, Pedro sentiu a necessidade de considerar uma nova indagação que até então só a considerava em teoria: afinal, quem era ele dentro daquele turbilhão de pensamentos? Ou entre os hiatos de silêncio que separava duas séries de pensamento? Seria apenas mais um pensamento que observava os outros pensamentos ou teria esse alguma qualidade diferenciada? Era como se Pedro pudesse agora colocar a sua mente em uma lupa poderosa, capaz de revelar camada após camada nuances até então despercebidas.

Após muitas tentativas de meditação, Pedro começara a vislumbrar algum alento, como quem ultrapassa uma forte arrebentação e alcança uma parte mais calma e tranquila do oceano. Uma vez ou outra as situações de lucidez deixavam de ser fugazes, tornaram-se visões mais lúcidas. Uma sensação de bem-estar começava a dominar sua prática e se transbordava para o seu dia-a-dia. Parecia, afinal, começar a entender a meditação.

\section{A Análise das Lógicas}

Esse ensaio mostra operantes em Pedro os quatro modos básicos de ser e de pensar - a lógica de Identidade (I), a lógica da diferença (D), a dialética (I/D), a lógica sistêmica $(\mathrm{D} / 2)$ - e mais um pensar síntese das anteriores, correspondente à lógica hiperdialética (I/D/2). As primeiras duas lógicas são autônomas e fundamentais, enquanto as outras três 
são formadas por construções sintéticas e ascendentes da interação entre as duas lógicas fundamentais. A cada um desses modos corresponde um modo de percepção da realidade.

\section{Lógica da identidade (I)}

$\mathrm{Na}$ prática meditativa, a lógica da identidade é a primeira a se fazer presente, com a constatação imediata, ainda que breve, de se tomar naquele momento de um propósito claro. Pedro tinha consciência de pertencer àquele local, naquele momento, e o propósito que deveria seguir durante o experimento. Apesar da influência das incertezas, a decisão de Pedro começar a meditar pertence a ele, faz parte de sua escolha e vontade. Os motivos contrários são muitos, o dia-a-dia cobra-lhe um preço elevado para aquela escolha.

Trata-se essencialmente de um exercício de autodeterminação ou livre-arbítrio. Ao entrar em meditação e se imbuir de seu ser no mundo, Pedro transcende a sua identidade e se torna um ser transcendental. Daí porque a lógica da identidade também é chamada de lógica transcendente (I).

\section{Lógica da diferença $(D)$}

Ao dar o segundo passo na meditação, Pedro sente sua consciência inundada por forças de natureza inconsciente. Com efeito, ele é tomado por diversos impulsos, em forma de sensações, sentimentos e pensamentos, tornando o seu esforço comprometido. Apesar do fracasso iminente, aquilata um ganho secundário, com o insight sobre a conversa que teve com o seu pai. Ao tentar se fixar no que acredita ser uma consciência profunda, Pedro é tomado pela lógica da diferença, aquela que não pede licença para se fazer presente. Tudo aí pode acontecer, inclusive e em especial o despertar da criatividade e a revelação de aspectos até então insuspeitos.

Qualquer iniciante na prática meditativa confronta-se com a vigorosa força desta lógica (D). Aceitar o seu modo de operação sem se perder por ele é um dos grandes desafios para a continuidade do exercício, o que será locupletado na lógica seguinte.

\section{Lógica dialética (I/D)}

Esta lógica corresponde ao modo de pensar síntese do mesmo e do outro. O "mesmo", neste ensaio, é a própria identidade do Pedro; o "outro" refere-se aos aspectos inconscientes que pululam em sua mente, disputando de forma deslizante e incerta o seu lugar na consciência. Dito de outra forma, é quando Pedro tenta fazer prevalecer seu esforço, mas se obrigado a levar em consideração outros argumentos ou demandas paradoxais, até então não claramente admissíveis.

Por isso diz-se que a lógica dialética nasce de um confronto, que busca uma conciliação ou um equilíbrio, entre as lógicas da identidade e da diferença. O duelo encontra agora uma solução em uma síntese que engendra duas realidades opostas, uma que fala por si e outra de sua multiplicidade. Ambas se mesclam e se compreendem dentro de uma 
perspectiva existencial. Cabe considerar que quando a identidade (I) é frágil, ainda pouco refletida ou consolidada, a lógica do inconsciente (D) domina inteiramente o ego, e a síntese (I/D) se torna difícil de ser alcançada.

A partir desta etapa, ainda que fraquejando aqui ou acolá, Pedro entende que quanto mais sólida o I/D, mais a prática pode caminhar para o estágio seguinte.

\section{Lógica sistêmica (D/D ou D/2) ou da dupla diferença}

Não é a primeira vez que o Pedro recorre a esta lógica, pois esta é rege o cálculo, aquela mesma que define uma verdade convencional, a própria lógica da ciência. Logo em seu início Pedro raciocina sobre a realização da prática meditativa, sobre seus atributos de valor (a partir do conhecimento que adquiriu sobre a meditação), analisa o espaço em que ela se realiza, aquiesce aos ensinamentos propostos, entendendo-os desde já por razoáveis. Em outro momento, quando exasperado, procura calcular o tempo que falta para o fim da meditação.

A lógica sistêmica projeta uma realidade externa, convencional, porém resta-nos ainda penetrar na janela interna da mente de Pedro.

Uma das chaves do conhecimento meditativo é quando constatamos a forma de funcionamento do ego, de suas características e história de sua criação, que definem suas particularidades e estimulam diferentes tipos de pensamentos, sentimentos ou ações. É uma percepção mais ambiciosa da aplicação da lógica clássica (D/2), exige um conhecimento mais refinado de si mesmo, que, quando consciente, à parte das histórias ensejadas pelo ego, proporciona uma mente altaneira. Isso será derradeiramente alcançado na lógica seguinte.

\section{Lógica hiperdialética (I/D/2)}

Vencidos os desafios das lógicas anteriores, aquilo que dantes capturava o Pedro a ponto de o fazer perder uma consciência aparentemente mais segura de si, já não o faz com a mesma frequência. Como praticante avançado, Pedro assiste ao mundo, interno e externo, de forma menos suscetível às respostas automáticas, aquelas que caracterizam a sua personalidade. Uma coisa era ter a racionalização que expresse o entendimento da prática meditativa (D/2), enquanto outra é aquilatar uma compreensão forte o suficiente para que a consciência esteja mais presente ( $/ \mathrm{D} / 2)$ sem que gere envolvimento ou dispersão. Como resultado de toda uma compreensão das lógicas anteriores, sua vontade e compreensão tornaram-se fortes o suficiente, e todo um conjunto de vivências vai se somando ao seu novo entendimento.

Esses estados meditativos, mesmo que fugazes, inauguram uma janela na mente para que a consciência contemple uma dimensão nova ou distinta. Pode-se chegar a um momento em que a consciência amplie para uma janela maior, a uma consciência contemplativa. Esta não se espelha em nada, ela simplesmente se funde ao universo, sem mais a 
necessidade de separar entre o "eu" e o "outro". Se tal possibilidade nos fosse dada, então estaríamos caminhando para uma lógica ainda mais elevada (I/D/3), que, segundo Sampaio, é inalcançável para a nossa espécie humana, apenas na melhor das hipóteses como um desejo de transcendência, ou talvez como um simulacro. Somente aos "anjos" seria permitido alcançar tal lógica. Talvez, então, tenhamos anjos insuspeitos dentro de nós.

\section{Em lugar da conclusão}

Uma razão mais profunda para a recusa a acompanhar a evolução do pensamento meditativo aqui explorada é que cada uma das lógicas, conforme nos ensinou Sampaio, tende a se sobrepor sobre as demais, a ficar fechada em si mesma do que se admitir como parte de um conjunto maior ordenado pela lógica hiperdialética. Dito de outra forma, a dificuldade da prática meditativa deve-se ao nosso atavismo lógico desorientado. Ademais, a mudança de uma lógica frequente se realiza com a perda de algum aspecto das lógicas anteriores, o que nos mantém em um estado de fixação lógica e de carência de estruturação. Reside aí a dificuldade maior em cada um de nós, indivíduos, em nos reconhecermos como constituídos por um conjunto de lógicas, ou, porque não dizer, dimensões psicológicas, pois cada qual tende a manter uma determinada lógica como a dominante, e qualquer mudança não se faz sem estabelecer fortes conflitos que se resvalam em vários sentidos (MORENO, E.L., GOMES, M.P., 2017).

Não obstante, a todo momento nós, seres humanos, somos capazes potencialmente de nos tornar conscientes "hiperdialeticamente" de nossas ações, internas ou externas, não importa se estamos ou não praticando meditação. É tarefa difícil, sem dúvida, pois as forças culturais que incidem repetidamente sobre nós impedem-nos de nos reconhecermos e agirmos num tal estado de existência e compreensão. Reside aí a importância de verter nossos esforços para uma prática meditativa que, como outras práticas de autoconscientização, possa nos ajudar a agirmos com mais clarividência e, quiçá, felicidade.

\section{Agradecimentos}

Ao Dr. Luiz Carlos Bernal pelas inestimáveis orientações sobre a prática meditativa.

\section{Financiamento}

O presente trabalho foi realizado com apoio da Coordenação de Aperfeiçoamento de Pessoal de Nível Superior - Brasil (CAPES) - Código de Financiamento 001. 


\section{Referências}

MORENO, E. L.; GOMES, M. P. A Territorialidade na Visão Lógica-Cultural Hiperdialética. Revista Scientiarum Historia, v. 1, n. 1, p. 8,7 nov. 2017. Disponível em: http://revistas.hcte.ufrj.br/index.php/RevistaSH/article/view/131 Acesso em: 20 de jul. de 2018.

SAMPAIO, L.S.C. de. Lógica Ressuscitada - Sete Ensaios, Rio de Janeiro, EdUERJ, 2000.

SAMPAIO, L. S. C. de. A lógica da diferença, Rio de Janeiro, EdUERJ, 2001.

SAMPAIO, Luiz Sérgio Coelho de. O inevitável exercício cotidiano de todas as lógicas. Biblioteca Luiz Sérgio Coelho de Sampaio (blogspot). 2002. Disponível em: http://luizsergiosampaio.blogspot.com/2017/10/o-inevitavel-exercicio-cotidiano-de.html Acesso em: 20 de ago. de 2018. 